\title{
Heterologous reconstitution of the biosynthesis pathway for 4-demethyl-premithramycinone, the aglycon of antitumor polyketide mithramycin
}

\author{
Daniel Zabala1,3, Lijiang Song ${ }^{3}$, Yousef Dashti ${ }^{3}$, Gregory L. Challis ${ }^{3,4,5}$, José A. Salas ${ }^{1,2}$ and Carmen Méndez ${ }^{1,2^{*}}$ (1)
}

\begin{abstract}
Background: Mithramycin is an anti-tumor compound of the aureolic acid family produced by Streptomyces argillaceus. Its biosynthesis gene cluster has been cloned and characterized, and several new analogs with improved pharmacological properties have been generated through combinatorial biosynthesis. To further study these compounds as potential new anticancer drugs requires their production yields to be improved significantly. The biosynthesis of mithramycin proceeds through the formation of the key intermediate 4-demethyl-premithramycinone. Extensive studies have characterized the biosynthesis pathway from this intermediate to mithramycin. However, the biosynthesis pathway for 4-demethyl-premithramycinone remains unclear.
\end{abstract}

Results: Expression of cosmid cosAR7, containing a set of mithramycin biosynthesis genes, in Streptomyces albus resulted in the production of 4-demethyl-premithramycinone, delimiting genes required for its biosynthesis. Inactivation of $m t m L$, encoding an ATP-dependent acyl-CoA ligase, led to the accumulation of the tricyclic intermediate 2-hydroxy-nogalonic acid, proving its essential role in the formation of the fourth ring of 4-demethyl-premithramycinone. Expression of different sets of mithramycin biosynthesis genes as cassettes in S. albus and analysis of the resulting metabolites, allowed the reconstitution of the biosynthesis pathway for 4-demethyl-premithramycinone, assigning gene functions and establishing the order of biosynthetic steps.

Conclusions: We established the biosynthesis pathway for 4-demethyl-premithramycinone, and identified the minimal set of genes required for its assembly. We propose that the biosynthesis starts with the formation of a linear decaketide by the minimal polyketide synthase MtmPKS. Then, the cyclase/aromatase MtmQ catalyzes the cyclization of the first ring (C7-C12), followed by formation of the second and third rings (C5-C14; C3-C16) catalyzed by the cyclase MtmY. Formation of the fourth ring (C1-C18) requires MtmL and MtmX. Finally, further oxygenation and reduction is catalyzed by MtmOII and MtmTI/MtmTII respectively, to generate the final stable tetracyclic intermediate 4-demethyl-premithramycinone. Understanding the biosynthesis of this compound affords enhanced possibilities to generate new mithramycin analogs and improve their production titers for bioactivity investigation.

\footnotetext{
*Correspondence: cmendezf@uniovi.es

${ }^{1}$ Departamento de Biología Funcional e Instituto Universitario de

Oncología del Principado de Asturias (I.U.O.P.A), University of Oviedo,

Oviedo, Spain

Full list of author information is available at the end of the article
}

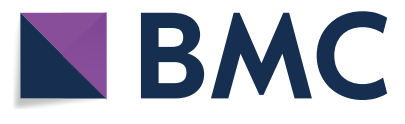

(c) The Author(s) 2020. This article is licensed under a Creative Commons Attribution 4.0 International License, which permits use, sharing, adaptation, distribution and reproduction in any medium or format, as long as you give appropriate credit to the original author(s) and the source, provide a link to the Creative Commons licence, and indicate if changes were made. The images or other third party material in this article are included in the article's Creative Commons licence, unless indicated otherwise in a credit line to the material. If material is not included in the article's Creative Commons licence and your intended use is not permitted by statutory regulation or exceeds the permitted use, you will need to obtain permission directly from the copyright holder. To view a copy of this licence, visit http://creativeco mmons.org/licenses/by/4.0/. The Creative Commons Public Domain Dedication waiver (http://creativecommons.org/publicdomain/ zero/1.0/) applies to the data made available in this article, unless otherwise stated in a credit line to the data. 
Keywords: Streptomyces argillaceus, Mithramycin, Premithramycinone, Aureolic acid, Acyl-CoA ligase, Cyclase,

Polyketide synthase

\section{Background}

Mithramycin (MTM) is an anti-tumor agent member of the aureolic acid family and is produced by Streptomyces argillaceus ATCC12956. MTM was approved as an anticancer drug in 1970 [1], but its use has been limited due to its toxic side effects. MTM acts as an anti-tumor agent by binding to $\mathrm{G} / \mathrm{C}$ rich regions located at gene promoters (Sp1 or Sp3), preventing the binding of transcription factors and thus blocking the action of Sp regulated genes [2]. In the past few years, new activities and other potential uses for MTM have been discovered, reviving interest in this compound [3-7]. In addition, new formulations for MTM have been developed (i.e. MTM-loaded nanoparticles) [8], and a MTM phase I/II trial was performed with children and adults with refractory Ewing sarcoma [9].

Structurally, MTM is a polyketide (PK) consisting of a tricyclic aglycone with two aliphatic side chains, which is glycosylated by a trisaccharide and a disaccharide [10]. The MTM biosynthesis gene cluster (BGC) $\mathrm{mtm}$ has been cloned and characterized [11]. This has allowed the generation of new MTM analogs through combinatorial biosynthesis strategies [12]. Some of these new analogs showed higher antitumor activity and/or lower toxicity than the parental compound [13-16], and were shown to affect the Ewing sarcoma xenograft growth and triple negative breast cancer growth in mice $[17,18]$. These promising activities have led to the development of these compounds as potential new anticancer drugs $[19,20]$, which requires sufficient amounts for preclinical and clinical trials.

Different approaches have been used to improve production of MTM and some analogs. These include overexpression of cluster specific regulators [21, 22], increasing and channeling the flux of MTM precursors using metabolic engineering strategies [23], and heterologous expression of the $m t m$ BGC [24]. Further improvements could be achieved using synthetic biology techniques [25]. This approach requires the identification of all genes involved in the biosynthesis of a compound and determination of the order in which the gene products act. The biosynthesis pathway of MTM proceeds through the formation of the tetracyclic aglycon 4-demethyl-premithramycinone (4DMPC). This is methylated and glycosylated to yield the tetracyclic intermediate premithramycin $B$, which undergoes oxidative cleavage at its fourth ring and a reduction of the resultant side chain to generate the final bioactive compound MTM [11]. All biosynthesis steps from 4DMPC to MTM have been identified and characterized through the generation of mutants and characterization of the accumulated compounds, by in vitro assays and/or by gene expression experiments $[11,12]$. However, the biosynthetic steps leading to 4DMPC are not completely understood. Here we report the in vivo reconstitution of the biosynthesis pathway for $4 \mathrm{DMPC}$, identifying the minimum set of genes required and the order of action of the gene products.

\section{Results and discussion}

\section{Delimiting the set of genes required}

for 4-demethyl-premithramycinone biosynthesis

The $m$ tm BGC contains thirty-four genes (Fig. 1a), some of which have been associated with the biosynthesis of 4DMPC [11, 12]: mtmP ( $\beta$-ketoacyl synthase $\alpha$ ), $m$ tmK ( $\beta$-ketoacyl synthase $\beta$ ) and $m t m S$ (acyl carrier protein),

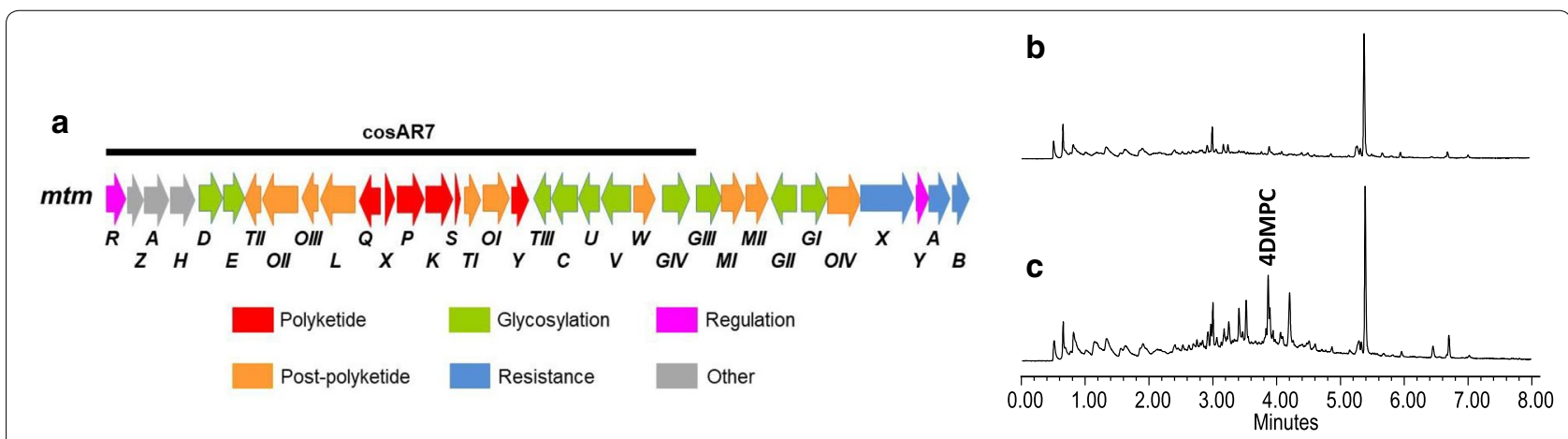

Fig. 1 Expression of cosAR7 in S. albus. a Genetic organization of cluster mtm from Streptomyces argillaceus. b UHPLC analysis at $280 \mathrm{~nm}$ of organic extracts of S. albus pKC505 (control). c UHPLC analysis at $280 \mathrm{~nm}$ of organic extracts of S. albus cosAR7-R. Black line indicates mtm genes contained in cosmid cosAR7. Chromatograms are shown at the same scale. 4DMPC, 4-demethyl-premithramycinone 
encoding the minimal polyketide synthase (PKS) [26, 27], the aromatase/cyclase MtmQ, the cyclase MtmY [28], and the oxygenase MtmOII [29-31]. Cosmid cosAR7 [27] (Fig. 1a) contains all these genes (Table 1), as well as some other genes proposed to be involved in the biosynthesis of 4DMPC, such as $m t m X$ and $m t m T I$ and $m t m T I I$, which encode a putative cyclase and two ketoreductases, respectively. It also includes genes that have been shown to be dispensable for MTM biosynthesis in S. argillaceus: $m t m O I$ and $m$ tmOIII [31] and $m t m Z, m t m A, m t m H$ (Fernández-Lozano, unpublished results); genes for deoxysugar biosynthesis ( $m t m D, m t m E$, mtmTIII, $m t m C$, $m t m U$ and $m t m V)$ [32, 33], and transfer (mtmGIV) [34], and a ketoreductase $(m t m W)$ involved in side chain reduction [35]. In addition, it contains $m t m L$, which encodes a putative acyl-CoA ligase. Therefore cosAR7 would have the potential capability to direct the biosynthesis of 4DMPC but not any other later biosynthesis intermediate since this cosmid lacks $m t m M I$ [36], which encodes the methyltransferase MtmMI that catalyzes an essential step in MTM biosynthesis that takes place before glycosylation and further reduction steps. To confirm the potentiality of cosAR7, it was introduced into Streptomyces albus to generate the recombinant strain
S. albus cosAR7 (Table 2). To ensure the correct expression of the $m$ tm genes, plasmid pFL3R [22] expressing the pathway specific transcriptional activator $m t m R$ was also introduced into $S$. albus cosAR7. As can be seen in Fig. 1c, the resultant strain (S. albus cosAR7-R; Table 2) was able to produce a compound with exactly the same absorptium spectrum and UHPLC retention time as the previously isolated mithramycin intermediate 4-DMPC [37]. This confirms that cosmid cosAR7 contains all the genes required for the biosynthesis of $4 \mathrm{DMPC}$, and excludes the involvement of other $\mathrm{mtm}$ genes in the biosynthesis of this biosynthesis intermediate.

\section{Role of $m t m L$ in mithramycin biosynthesis}

CosAR7 contains $m t m L$, encoding a putative acyl-CoA ligase, whose role is unclear. Comparison of the MtmL sequence with those of proteins in databases showed similarity with acyl-CoA ligases such as CmmLII, PokL and SsfL2 (53\%, 49\% and 45\% of identical aminoacids, respectively), encoded by the chromomycin $\mathrm{A}_{3}$, polyketomycin and tetracycline SF2575 BGCs, respectively [3840] (Additional file 1: Figure S1) Based on the similarity of MtmL with other acyl-CoA ligases, it was initially proposed that it could play a role in supplying acetyl-CoA to

Table 1 Functions of gene products from cosAR7

\begin{tabular}{|c|c|c|c|c|}
\hline Gene & aa & Proposed function & Similar protein (acc. number) & $\begin{array}{l}\text { Identica } \\
\text { aa (\%) }\end{array}$ \\
\hline$m t m Z$ & 260 & Putative thioesterase & WP_164185915.1 & 84 \\
\hline$m t m A$ & 460 & Methylenetetrahydrofolate reductase & WP_043385055.1 & 83 \\
\hline$m t m H$ & 482 & Adenosylhomocysteinase & WP_164185914.1 & 94 \\
\hline$m t m D$ & 355 & Glucose-1P thymidylyltransferase & WP_164189839.1 & 88 \\
\hline$m t m E$ & 331 & dTDP-glucose 4,6-dehydratase & WP_164189984.1 & 91 \\
\hline$m t m T I I$ & 253 & Ketoreductase & WP_164189846.1 & 90 \\
\hline mtmOIl & 531 & Oxygenase & WP_078655152.1 & 84 \\
\hline mtmOIII & 99 & Monooxygenase & WP_164189850.1 & 87 \\
\hline$m t m L$ & 514 & Acyl-CoA ligase & WP_051703560.1 & 80 \\
\hline$m t m Q$ & 315 & Aromatase & WP_164189988.1 & 89 \\
\hline$m t m x$ & 150 & Putative cyclase & WP_030997656.1 & 81 \\
\hline$m t m P$ & 422 & beta-ketoacyl-(ACP) synthase & WP_030997655.1 & 93 \\
\hline$m t m K$ & 408 & Ketosynthase chain-length factor & WP_164189853.1 & 88 \\
\hline$m t m s$ & 85 & Acyl carrier protein & WP_164189855.1 & 82 \\
\hline$m t m T l$ & 254 & Ketoreductase & WP_164189991.1 & 86 \\
\hline$m t m O l$ & 436 & FAD-binding monooxygenase & WP_164189993.1 & 86 \\
\hline$m t m Y$ & 257 & Cyclase & WP_164189857.1 & 91 \\
\hline mtmTIII & 247 & Ketoreductase & WP_164189858.1 & 89 \\
\hline$m t m C$ & 420 & D-mycarose 3-C-methyltransferase & WP_164189995.1 & 91 \\
\hline$m t m U$ & 328 & D-oliose 4-ketoreductase & WP_030997647.1 & 80 \\
\hline$m t m V$ & 486 & NDP-hexose 2,3-dehydratase & WP_164189860.1 & 84 \\
\hline$m t m W$ & 326 & Aldo/keto reductase & WP_164189862.1 & 89 \\
\hline$m t m G I V$ & 407 & Glycosyltransferase & WP_164189864.1 & 89 \\
\hline
\end{tabular}


Table 2 Plasmids and Streptomyces argillaceus and Streptomyces albus strains generated in this work

\begin{tabular}{|c|c|c|}
\hline Plasmid & Expressed gene(s) & Vector used \\
\hline pDZL10 & $m t m L$ & pEM4T \\
\hline pDZPKS1 & $m t m P K S$ & pEM4 \\
\hline pDZPKSQ & $m t m P K S Q$ & pEM4 \\
\hline pDZPKS2 & $m t m P K S L$ & pEM4 \\
\hline pDZPKS3 & $m t m P K S L Q$ & pEM4 \\
\hline pDZPKS4 & $m t m P K S L Q X$ & pEM4 \\
\hline pDZPKS5 & $m t m P K S L Q X Y$ & pEM4 \\
\hline pDZPKS6 & $m t m P K S L Q X Y O I I$ & pEM4 \\
\hline pDZPKS7 & $m t m P K S L Q X Y O I T I$ & pEM4 \\
\hline pDZPKS8 & $m t m P K S L Q Y$ & pEM4 \\
\hline pDZPKS9 & $m t m P K S Q Y$ & pEM4 \\
\hline pDZPKS10 & mtmPKSQYTI & pEM4 \\
\hline pDZPKS11 & $m t m P K S Q Y X$ & pEM4 \\
\hline pDZPKS12 & mtmPKSQXYOIITITII & pEM4 \\
\hline pDZPKS13 & mtmPKSQYXOIITII & pEM4 \\
\hline pDZPKS14 & mtmPKSLQXYOIITITII & pEM4 \\
\hline pDZPKS15 & $m t m O I I$ & pEM4AT \\
\hline pDZPKS19 & $m t m O I I T I$ & pEM4AT \\
\hline pDZPKS21 & mtmOIITI & pEM4AT \\
\hline Recombinant/mutant strain & Inactivated/expressed gene(s) & Plasmid used \\
\hline S. argillaceus $\Delta \mathrm{L}$ & $m t m L$ & $\mathrm{p} \Delta \mathrm{L}$ \\
\hline S. argillaceus $\Delta \mathrm{L}-\mathrm{pDZL} 10$ & $m t m L$ & pDZL10 \\
\hline S. argillaceus pDZL10 & $m t m L$ & pDZL10 \\
\hline S. argillaceus pEM4T & - & pEM4T \\
\hline S. albus cosAR7 & mtmZAHDETIIOIIOIILQXXPKSTIOIYTIIICUVWGIV & $\cos A R 7$ \\
\hline \multirow[t]{2}{*}{ S. albus cosAR7-R } & mtmZAHDETIIOIIOIILQXXPKSTIOIYTIIICUVWGIV & $\cos A R 7$ \\
\hline & $m t m R$ & $\mathrm{pFL3R}$ \\
\hline S. albus pEM4 & - & pEM4 \\
\hline S. albus pDZPKS1 & $m t m P K S$ & pEM4 \\
\hline S. albus pDZPKSQ & $m t m P K S Q$ & pEM4 \\
\hline S. albus pDZPKS9 & mtmPKSQY & pEM4 \\
\hline S. albus pDZPKS10 & mtmPKSQYTI & pEM4 \\
\hline S. albus pDZPKS11 & $m t m P K S Q Y X$ & pEM4 \\
\hline S. albus pDZPKS12 & mtmPKSQXYOIITITII & pEM4 \\
\hline S. albus pDZPKS13 & mtmPKSQYXOIITII & pEM4 \\
\hline S. albus pDZPKS8 & $m t m P K S L Q Y$ & pEM4 \\
\hline S. albus pDZPKS5 & $m t m P K S L Q X Y$ & pEM4 \\
\hline \multirow[t]{2}{*}{ S. albus pDZPKS5+15 } & $m t m P K S L Q X Y$ & pEM4 \\
\hline & mtmOll & pEM4AT \\
\hline \multirow[t]{2}{*}{ S. albus pDZPKS8+15 } & $m t m P K S L Q Y$ & pEM4 \\
\hline & $m t m O l l$ & pEM4AT \\
\hline \multirow[t]{2}{*}{ S. albus pDZPKS5+21 } & $m t m P K S L Q X Y$ & pEM4 \\
\hline & mtmTIIOIITI & pEM4AT \\
\hline
\end{tabular}

the MTM pathway [31]. More recently, it has been found that some ATP-dependent acyl-CoA ligases such as SsfL2 and $\mathrm{OxyH}$ are involved in formation of the fourth ring of tetracyclines, and that MtmL could fulfill such a role when combined with tetracycline biosynthesis enzymes $[41,42]$. To determine the role of $m t m L$ in the MTM pathway, this gene was initially overexpressed in the $S$. argillaceus wild type strain using plasmid pDZL10 (Table 2 
and Additional file 1). MTM production in the resultant recombinant strain (S. argillaceus pDZL10; Table 2) was $29 \%$ higher than in the control strain (S. argillaceus pEM4T) (Additional file 1: Figure S2). This result supported a role for MtmL in supplying precursors for the biosynthesis of the MTM aglycon. Then, $m t m L$ was inactivated in S. argillaceus by replacing the wild type copy of this gene by a mutated one using plasmid $\mathrm{p} \Delta \mathrm{L}$ (Table 2 and Additional file 1: Figure S3). This plasmid contains an apramycin resistance cassette ( $a a c(3) I V)$ cloned into $m t m L$ in the same direction of transcription to avoid a polar effect on downstream genes. The resultant mutant strain (S. argillaceus $\Delta \mathrm{L}$; Table 2) did not produce MTM, but two new metabolites were detected instead (Fig. 2b). The major compound showed an absorbance maximum at $289 \mathrm{~nm}$ and had an $[\mathrm{M}+\mathrm{H}]^{+}$ion with $m / z=385.0936$, corresponding to the molecular formulae $\mathrm{C}_{20} \mathrm{H}_{16} \mathrm{O}_{8}$. Purification and structural characterization of this compound by NMR spectroscopy and MS (Additional file 2) showed it is the shunt product SEK15 (1, Fig. 3). This

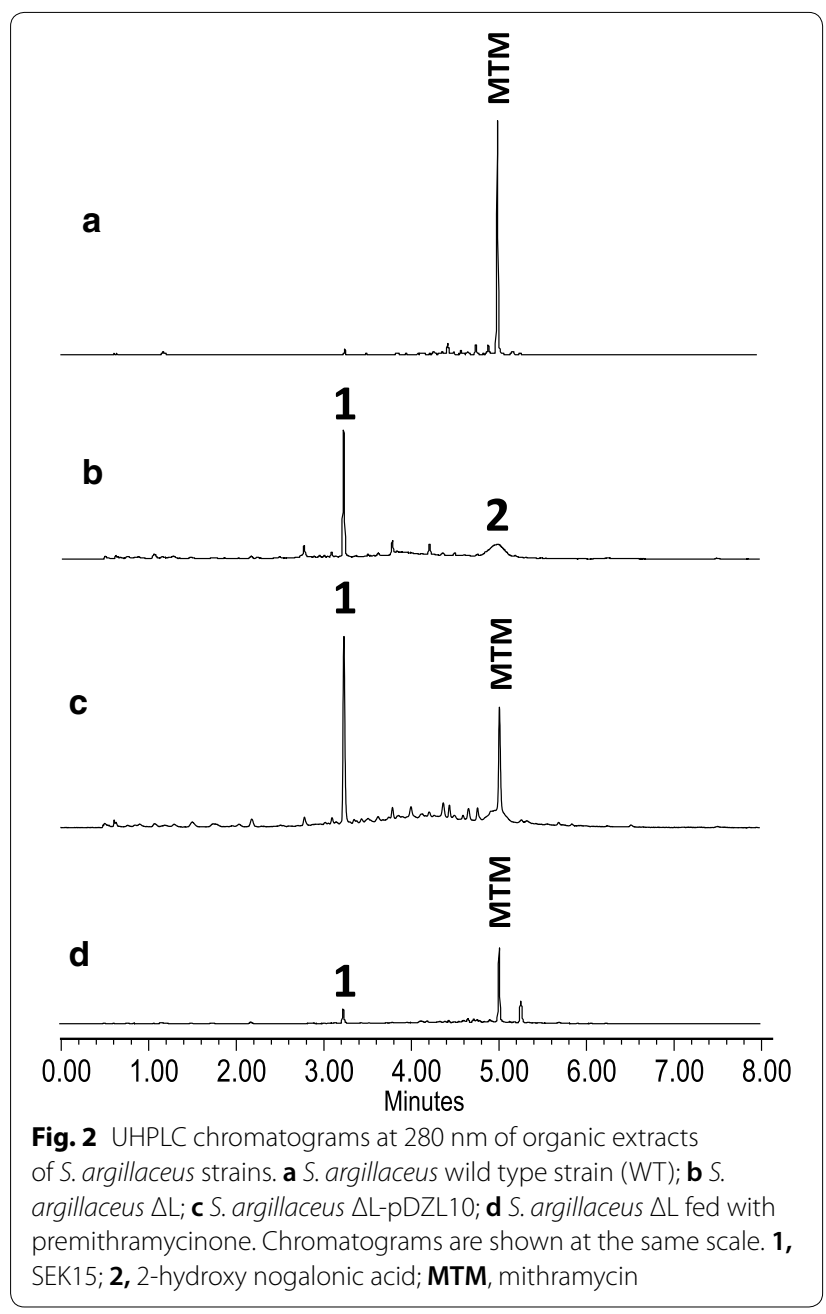

compound is generated by spontaneous cyclization of the 20 -carbon polyketide chain assembled by the minimal PKS [26], and it was detected for the first time in S. coelicolor $\mathrm{CH}$ 999, expressing the minimal PKS from the tetracenomycin biosynthesis pathway [43]. Production of this compound disproved the proposed role for MtmL in supplying acetyl-CoA units for the biosynthesis of the MTM polyketide chain. The second major compound exhibited an absorbance maximum at $290 \mathrm{~nm}$ and a molecular formulae of $\mathrm{C}_{20} \mathrm{H}_{14} \mathrm{O}_{9}$ was obtained from HR-ESI-MS $(\mathrm{m} / \mathrm{z}$ calculated for $[\mathrm{M}+\mathrm{H}]^{+}$: 399.0711; observed: 399.0710). This compound was purified and structurally characterized by NMR spectroscopy and MS (Additional file 3), which showed to be the tricyclic quinone 2-hydroxy nogalonic acid (2, Fig. 3). This compound has been proposed to be an intermediate in steffimycin biosynthesis and is produced in the absence of the fourth ring cyclase [44]. Thus, MtmL most probably is required for cyclization of the fourth ring of $4 \mathrm{DMPC}$ and acts prior to oxygenation of the aglycon.

To confirm that $S$. argillaceus $\Delta \mathrm{L}$ was only affected in $m t m L$, this strain was complemented using plasmid pDZL10 (Table 2). As can be observed in Fig. 2c, MTM production was restored in the resulting strain (S. argillaceus $\Delta \mathrm{L}$-pDZL10; Table 2). Moreover, the mutant strain was chemically complemented by growing it in the presence of $50 \mu \mathrm{g} / \mathrm{mL}$ premithramycinone. This compound is a MTM biosynthesis intermediate, accumulated by the $S$. argillaceus M7G4 mutant that is affected in the mtmGIV glycosyltransferase gene [34]. In the MTM biosynthesis pathway, premithramycinone is generated by methylation of 4DMPC by the methyltransferase MtmMI [36]. Samples obtained after $48 \mathrm{~h}$ of incubation in the presence of premithramycinone showed its complete conversion into MTM (Fig. 2d). All these results confirm that blockage of MTM production in $S$. argillaceus $\Delta \mathrm{L}$ is due solely to the mutation of $m t m L$ and supports a role for MtmL in the biosynthesis of the MTM aglycon, after initial polyketide chain assembly. They also suggest that MtmL and/or its reaction product is limited within the pathway, since overexpression of $m t m L$ in the wild type strain results in an increase in MTM production. Improvement of production yields by overexpression of structural genes has also been observed in other biosynthetic pathways [45].

\section{In vivo reconstitution \\ of the 4-demethyl-premithramycinone biosynthetic pathway}

Based on the above results, we aimed to reconstitute the biosynthesis pathway for $4 \mathrm{DMPC}$ in vivo to determine the minimal set of genes required and the order of biosynthetic steps. To do this, we used gene cassettes flanked by unique restriction sites to create artificial operons 


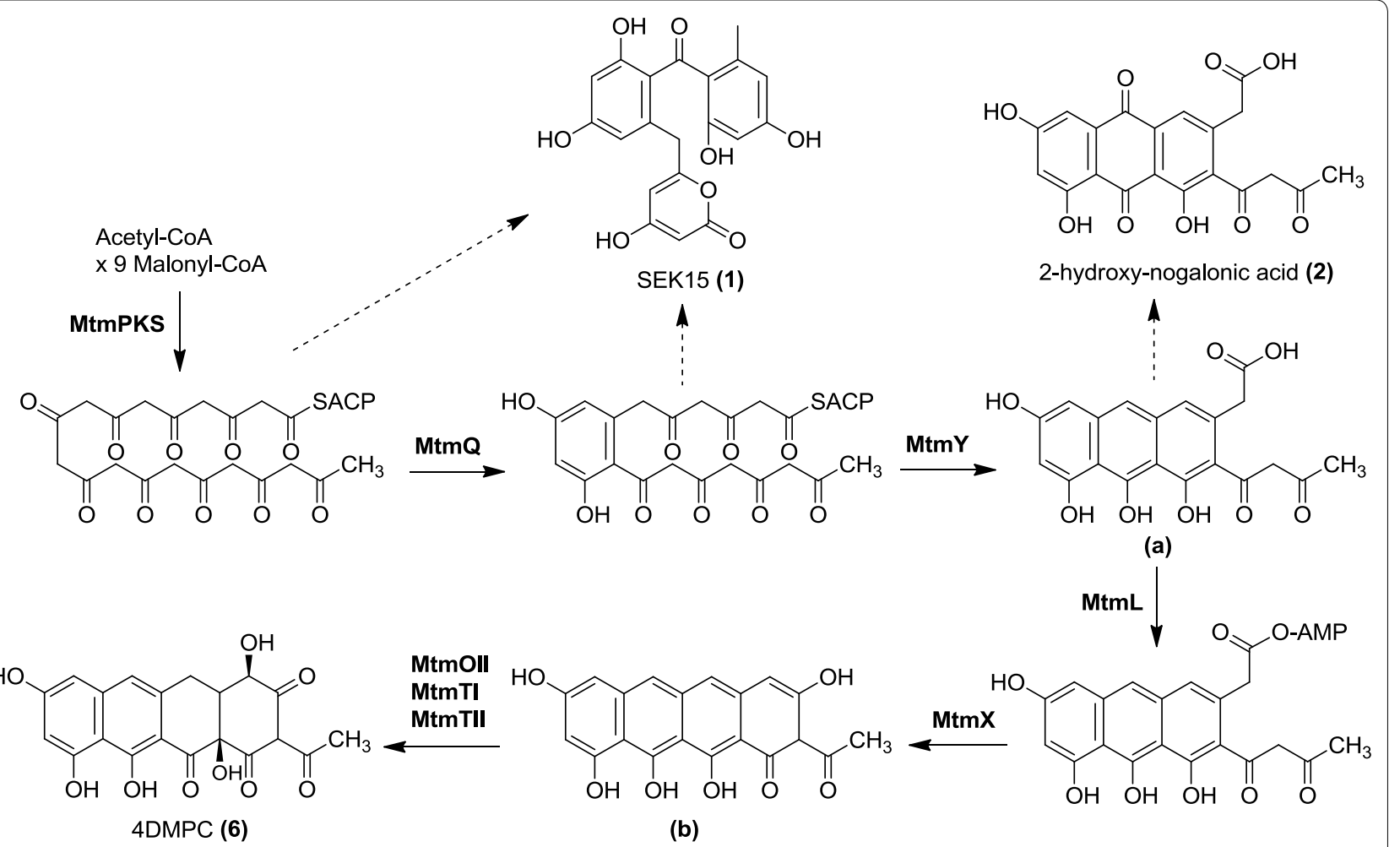

Fig. 3 Proposed biosynthesis pathway for 4-demethyl-premithramycinone. Dashed lines represent formation of shunt products

under the control of the $e r m E^{*}$ promoter containing different combinations of the $m t m Q, m t m X, m t m Y$, $m$ tmOII, $m$ tmTI and $m$ tmTII genes (Table 1) downstream from an operon containing the $m t m P, m t m K$ and $m t m S$ genes (Fig. 4, Table 2 and Additional file 4). The resulting plasmids were introduced into $S$. albus, and the metabolites produced by the resultant strains (Table 2) were compared using UHPLC analyses (Fig. 5).

The strain containing a construct (pDZPKS1) expressing just the $m t m P, m t m K$ and $m t m S$ genes, which encode the minimal PKS, produced the shunt metabolite SEK15 (1) that shows a C7-C12 cyclization (Table 2, Figs. 3 and $5 \mathrm{~b})$. This metabolite was absent from the control strain (S. albus pEM4; Table 2 and Fig. 5a). Production of SEK15 by $S$. albus pDZPKS1 agrees with reports that indicate that the minimal PKS is sufficient to determine the regioselective C7-C12 cyclisation [46]. MtmQ contains an $\mathrm{N}$-terminal and $\mathrm{C}$-terminal aromatase/cyclase domains (cd08861), and it shows similarity to putative non-reducing di-domain aromatases/cyclases [47], such as WP_164189988.1 and WP_030997657.1 (89\% and 85\% identical aminoacids, respectively) or StfQ from the steffimycin BGC [44] (53\% identical aminoacids. MtmQ was proposed to be involved in the cyclisation between $\mathrm{C} 7$ and C12 [48], which was later on confirmed by expressing in Escherichia coli $m t m Q$ together with an engineered fungal PKS that does not promote this type of cyclisation [49]. When $m t m Q$ was co-expressed with $m t m P K S$ using plasmid pDZPKSQ (Table 2 and Fig. 4) the metabolite profile did not change, but the titre of $\mathbf{1}$ increased about 25\% (Fig. 5c). This increase can be explained by MtmQ cyclisating and/or facilitating and accelerating the proper cyclisation pattern of the polyketide chain, as it has been previously suggested [47].

MtmY shows similarity to cyclases involved in second and third ring formation in aromatic polyketide biosynthesis, such as KstD1 (71\%), StfY (69\%), DspY (68\%) and OxyN (68\%) from the kosinostatin, steffimycin, daunorubicin and oxytetracycline pathways, respectively $[44,50-$ 52]. Co-expression of $m t m Y$ with $m t m P K S$ and $m t m Q$ (using pDZPKS9; Table 2 and Fig. 4) led to the production of 2-hydroxy nogalonic acid (2), in addition to 1 (Figs. 3 and 5d). This result supports the role of MtmY as a cyclase involved in formation of the second and third rings and agrees with results from in vitro assays using MtmY in combination with enzymes from other pathways [28]. Addition of the putative ketoreductases encoded by $m t m T I$ and $m t m T I I$, the oxygenase encoded by $m t m O I I$ and/or the cyclase encoded by $m t m X$, which is proposed to be involved in formation of the fourth ring 


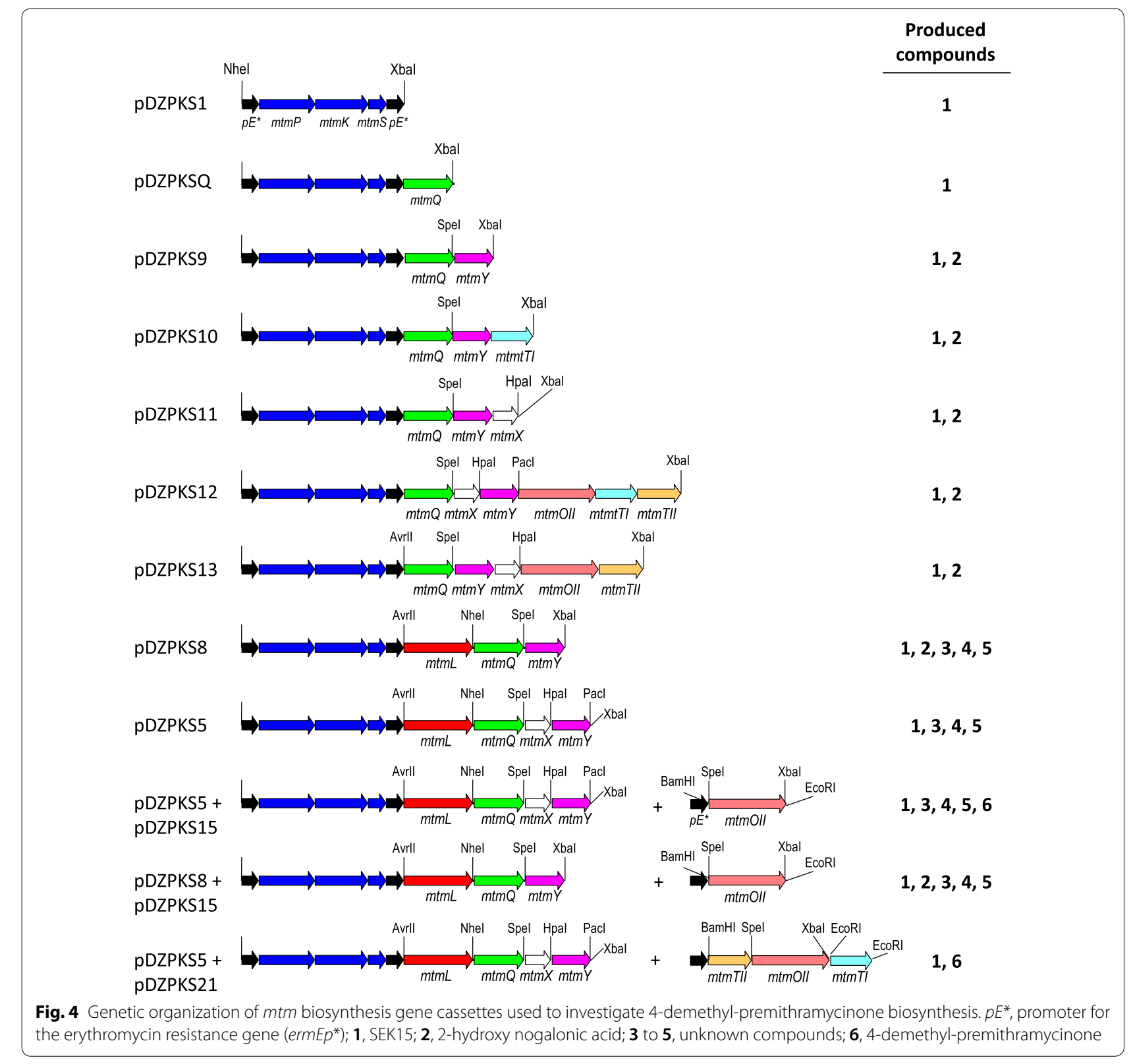

[53] (using plasmids pDZPKS10, pDZPKS11, pDZPKS12 and pDZPKS13; Table 2 and Fig. 4) did not alter the product profiles. This result and the fact that $S$. argillaceus $\triangle \mathrm{L}$ and $S$. albus-pDZPKS9 showed similar metabolite profiles (see Figs. 2b and 5 d) suggests MtmL acts immediately after MtmY. Therefore, we co-expressed $m t m L$ together with $m t m P K S, m t m Q$ and $m t m Y$ (using plasmid pDZPKS8; Table 2 and Fig. 4). The resulting strain (S. albus pDZPKS8) had a modified metabolite profile (Fig. 5e): in addition to compounds $\mathbf{1}$ and $\mathbf{2}$, this strain produced three new metabolites (compounds 3 to 5), with retention times of $6.3,7$ and $7.3 \mathrm{~min}$, respectively.
Additional expression of $m t m X$ (pDZPKS5; Table 2 and Fig. 4) did not alter the metabolite profile, but the titres of compounds 3, $\mathbf{4}$ and $\mathbf{5}$ increased, whereas the production of compounds $\mathbf{1}$ and $\mathbf{2}$ was significantly reduced (Fig. 5f). Unfortunately, the low yields and instability of these compounds did not permit their purification and structural characterization, but the fact that they were only produced when $m t m L$ (and $m t m X$ ) were co-expressed and they showed longer retention times than compound 2, indicates they might be tetracyclic. These results confirm MtmL plays an essential role in the biosynthesis of the MTM aglycon and are consistent with its proposed role 


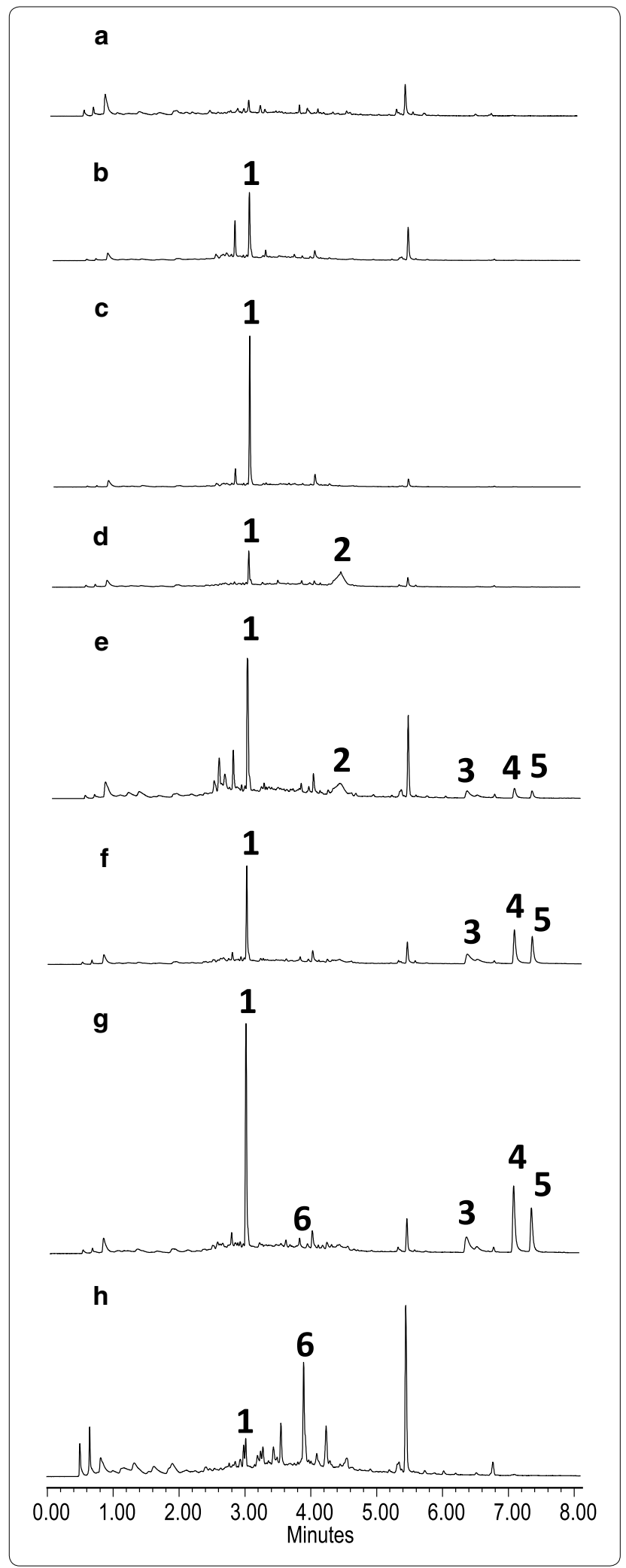

Fig. 5 UHPLC analysis at $280 \mathrm{~nm}$ of organic extracts of S. albus strains expressing different cassette plasmids. a S. albus pEM4 (control); b S. albus pDZPKS1; c S. albus pDZPKSQ; d S. albus pDZPKS9; e S. albus pDZPKS8; $\mathbf{f}$ S. albus pDZPKS5; $\mathbf{g}$ S. albus pDZPKS5 + 15; $\mathbf{h}$ S. albus PDZPKS5 +21. Chromatograms are shown at the same scale. 1, SEK15; 2, 2-hydroxy nogalonic acid; $\mathbf{3 - 5}$, unknown compounds; 6 , 4-demethyl-premithramycinone

as cyclase involved in formation of the fourth ring [42]. MtmL likely adenylates the carboxyl group in the product of MtmY. The resulting acyl adenylate is activated towards cyclisation by attack of an enolate derived from deprotonation of the 1,3-diketone. We also suggest that MtmX and MtmL cooperate in this process, since expression of $m t m X$ improved production of compounds 3 to 5. MtmX is homologous to SnoaL-family of enzymes that have been shown to mediate fourth ring closure in the biosynthesis of other aromatic polyketides [54]. In addition, MtmX is similar to StfX (49\% identical aminoacids) from the steffimycin biosynthesis pathway, which has been proposed to play a role in facilitating formation of the fourth ring [44] and has been recently suggested to be responsible, together with ketoreductase StfT, for cyclization between $\mathrm{C} 2$ and $\mathrm{C} 19$ of presteffimycinone [28]. Thus, we propose that, in the MTM pathway, cyclisation of the product of MtmL to form the fourth ring can occur spontaneously, but is inefficient and that MtmX catalyses the reaction. This accounts for the increase in the production of 3, $\mathbf{4}$ and $\mathbf{5}$ when MtmX is co-expressed with MtmL. Previous studies on MTM biosynthesis showed that $m t m O I I$ is essential for $4 \mathrm{DMPC}$ production [29, 31]. Therefore, we co-expressed mtmOII (pDZPKS15; Table 2 and Fig. 4) in S. albus with pDZPKS5. The resulting strain (S. albus pDZPKS5 +15; Table 2 and Fig. 4) produced a small amount of 4DMPC (compound $\mathbf{6}$ in Fig. $5 \mathrm{~g}$ ). Expression of $m t m O I I$ in the absence of $m t m X$ (pDZPKS8 plus pDZPKS15; Table 2 and Fig. 4) did not lead to the production of $4 \mathrm{DMPC}$, establishing that $\mathrm{MtmX}$ is required for $4 \mathrm{DMPC}$ biosynthesis and that MtmOII acts after MtmL and MtmX. Co-expression of $m t m T I$ and $m$ tmTII with $m$ tmOII (pDZPKS21; Table 2 and Fig. 4) and pDZPKS5 caused an increase in 4DMPC (6) production and the disappearance of compounds 3 to 5 (Fig. 5h).

These results demonstrate that the minimal set of enzymes required for the biosynthesis of $4 \mathrm{DMPC}$ is the minimal PKS MtmPKS, the aromatase MtmQ, cyclases MtmY and MtmX, the acyl-CoA ligase MtmL, the oxygenase MtmOII, and ketoreductases MtmTI and MtmTII. 
They also show that oxygenases MtmOI and MtmOIII are not required for the biosynthesis of 4DMPC, despite early proposals to the contrary [29]. Based on these results, we propose a pathway for 4DMPC biosynthesis (Fig. 3). This is initiated by the condensation of one acetyl-CoA and nine malonyl-CoA units catalyzed by the type II minimal PKS MtmPKS to generate a decaketide that spontaneously cyclises to afford the shunt product SEK15 (1). Then, the aromatase/cyclase MtmQ, followed by the cyclase MtmY form the first $(\mathrm{C} 7-\mathrm{C} 12)$, second (C5-C14) and third $(\mathrm{C} 3-\mathrm{C} 16)$ rings, generating a putative intermediate a. Spontaneous oxidation of the second ring to a quinone, a process that has also been observed for other aromatic polyketides [50], results in the formation of 2-hydroxy-nogalonic acid (2). Next, MtmL adenylates the carboxyl group of compound a and collaborates with $\mathrm{MtmX}$ to form the fourth ring (between $\mathrm{C} 1-\mathrm{C} 18$ ), generating the putative intermediate $\mathbf{b}$, and oxygenation by MtmOII, followed by reduction by MtmTI and MtmTII, affords 4DMPC (6). Oxygenation of intermediate b could involve its epoxidation followed by reductive opening of the epoxide, as previously proposed [29].

In this pathway, MtmL and MtmX form the fourth ring prior to the oxidation and reduction reactions. This hypothesis is supported by the following facts: (i) inactivation of $m t m L$ in $S$. argillaceus (mutant $\Delta \mathrm{L}$ ) interrupts MTM biosynthesis and results in accumulation of 2-hydroxy-nogalonic acid (2); (ii) heterologous expression of $m t m P K S Q Y$ leads to the formation of 2-hydroxy-nogalonic acid (2) and in the absence of $m t m L$, expression of $m t m X, m t m O I I, m t m T I$ and/or $m$ tmTII does not modify the metabolite profile, indicating that MtmL acts before the products of these genes; (iii) Co-expression of $m t m L$ with $m t m P K S Q Y$ results in the production of new compounds $3, \mathbf{4}$ and 5 , the titres of which are increased by co-expression of $m t m X$; and (iv) in the absence of $m t m X$, co-expression of $m t m O I I$ and $m$ tmPKSQYL does not lead to the production of new compounds, suggesting that $\mathrm{MtmX}$ is required for biosynthesis to proceed and acts before MtmOII.

\section{Conclusions}

The pathway to 4DMPC, a key intermediate in MTM biosynthesis, has been established through in vivo reconstitution in $S$. albus, using a sequential expression approach employing $m t m$ gene cassettes. This has allowed the assignment of gene functions and determination of the order of biosynthetic steps. Understanding the biosynthetic pathway for 4DMPC will pave the way for improving the titre of MTM and analogs via synthetic biology approaches, and will facilitate rational creation of novel derivatives by metabolic engineering strategies. In addition, the gene cassette approach we employed here could be used in mix and match experiments with genes from other aromatic polyketide biosynthetic pathway and to reconstitute the biosynthesis of other aromatic polyketide aglycons.

\section{Methods}

\section{Strains and culture conditions}

S. argillaceus ATCC12956 a mithramycin producer, was used for gene replacement experiments. S. albus J1074 [55] was used as a host for heterologous reconstitution of the 4DMPC biosynthesis pathway. Sporulation of strains was achieved by growing them for 7 days at $30{ }^{\circ} \mathrm{C}$ on plates containing medium A [56]. Preparation of Streptomyces protoplasts, transformation, and selection of transformants was carried out as described [55]. Escherichia coli ET12567 (pUB307) was used as donor for intergeneric conjugation [55]. E. coli DH10B (Invitrogen) was used as a host for subcloning. Metabolite production was carried out on R5A solid medium [56] for 8 days and three independent cultures were performed for each production experiment as previously described [23]. Bioconversion experiments were carried out using a two-step culture method as previously described [57], except that cultivation in R5A liquid medium was carried out for $24 \mathrm{~h}$ before $50 \mu \mathrm{g} / \mathrm{ml}$ of premithramycinone were added to the culture. Compounds produced were analyzed after further $48 \mathrm{~h}$ of incubation in the presence of that metabolite. When plasmid-containing clones were grown, the medium was supplemented with the appropriate antibiotics: 5 or $25 \mu \mathrm{g} / \mathrm{ml}$ thiostrepton for liquid and solid cultures, respectively; $100 \mu \mathrm{g} / \mathrm{ml}$ ampicillin; $25 \mu \mathrm{g} / \mathrm{ml}$ apramycin; $25 \mu \mathrm{g} / \mathrm{ml}$ kanamycin; $25 \mu \mathrm{g} / \mathrm{ml}$ chloramphenicol and $25 \mu \mathrm{g} / \mathrm{ml}$ nalidixic acid.

\section{DNA manipulation and plasmids}

Plasmid DNA preparations, restriction endonuclease digestions, and other DNA manipulations were according to standard procedures for Streptomyces and for $E$. coli $[55,58]$. PCR amplifications were carried out using a Platinum Pfx DNA Polymerase (Invitrogen) and performed in a thermocycler (MyCicler Thermal Cycler System; Bio-Rad). pCR-blunt (Invitrogen), pIJ2925 [55], pUK21 [59], pEM4T [60], pEM4AT [61], pEM4 [61], and pBSKT [22], were used for subcloning. Plasmid pEFBA [36] was used as a source of the apramycin resistance cassette. Cosmid cosAR7 [27] was used as a source of $S$. argillaceus DNA for 4DMPC production.

\section{Generation of cassette plasmids for 4DMPC production}

Several genes from the $m t m$ BGC were amplified and sequenced using the primers listed in Additional file 4: Table S3. Multicistronic cassettes were constructed using $\mathrm{XbaI} / \mathrm{SpeI} / \mathrm{NheI} / \mathrm{AvrII} / \mathrm{HpaI} / \mathrm{PacI}$ compatible ends to 
facilitate several combinations in the vectors pEM4 and pEM4AT. Detailed description on plasmids generation is presented in Additional file 4, and are shown in Table 2 and Fig. 4.

\section{Generation of mutant S. argillaceus $\Delta \mathrm{L}$}

To this aim, plasmid $\mathrm{p} \Delta \mathrm{L}$ (Table 2) was generated as described in Additional file 1. This construct contains most of the $m t m L$ gene replaced by the apramycin cassette in the same direction of transcription. The plasmid $\mathrm{p} \Delta \mathrm{L}$ was used to transform $S$. argillaceus protoplasts. Transformants were selected with apramycin and tested for their susceptibility to thiostrepton. PCR analysis and sequencing using primers LF and Q (Additional file 1: Figure S3) were performed to confirm the replacement of the wild type copy of $m t m L$ by the mutated one (Additional file 1: Figure S3).

\section{Metabolite analysis, purification and structure elucidation}

Extraction and spectroscopic analyses of metabolites produced by $S$. argillaceus strains were carried out as described [23]. For the UHPLC analyses of $S$. albus metabolites, samples were eluted with $10 \%$ acetonitrile during $1 \mathrm{~min}$, followed by a linear gradient from $10 \%$ to $100 \%$ acetonitrile in $7 \mathrm{~min}$, at a flow rate of $0.5 \mathrm{~mL} /$ min and a column temperature of $35{ }^{\circ} \mathrm{C}$. Production and purification of SEK15 1 and 2-hydroxy nogalonic acid 2 was carried out by growing $S$. argillaceus $\Delta \mathrm{L}$ in $1 \mathrm{~L}$ of R5A solid medium. Plates were inoculated with $25 \mu \mathrm{l}$ of spores $\left(10^{6}\right.$ spores $\left./ \mathrm{mL}\right)$, incubated for 7 days at $30^{\circ} \mathrm{C}$ and extracted with 1:1 volume of ethyl acetate. The organic extract was evaporated under vacuum and purified by semi-preparative HPLC using an Agilent 1200 instrument fitted with a C-18 column $(100 \times 21 \mathrm{~mm}, 5 \mu \mathrm{m}$, Agilent). The following elution profile with a flow rate of $9 \mathrm{~mL} / \mathrm{min}$ was applied: an isocratic condition of $5 \%$ acetonitrile for $5 \mathrm{~min}$, followed by $45 \mathrm{~min}$ linear gradient to $100 \%$ acetonitrile. The purified samples were analyzed by high resolution UHPLC-MS on a Bruker MaXis Impact electrospray ionization time-of-flight mass spectrometer (ESI-TOF-MS) connected to a Dionex 3000 RS UHPLC instrument with UV absorption detected at $280 \mathrm{~nm}$ and fitted with an Agilent Zorbax Eclipse Plus C18 column $\left(100 \times 2.1 \mathrm{~mm}, 1.8 \mu \mathrm{m}, 25^{\circ} \mathrm{C}\right)$ at a flow rate of $0.2 \mathrm{~mL} / \mathrm{min}$ using the following elution program: $0 \mathrm{~min}, 5 \% \mathrm{ACN} / 95 \%$ $\mathrm{H}_{2} \mathrm{O} ; 12$ min, 100\% ACN; 17 min 100\% CAN (both ACN and $\mathrm{H}_{2} \mathrm{O}$ contained $0.1 \%$ formic acid). The NMR spectra were recorded at $25{ }^{\circ} \mathrm{C}$ in DMSO-d6 for SEK15 and $\mathrm{CD}_{3} \mathrm{OD}$ for 2-hydroxy nogalonic acid on a Bruker Avance II $700 \mathrm{MHz}$ spectrometer. Structure elucidation of $\mathbf{2}$ was carried out using a combination of $1 \mathrm{D}$ and $2 \mathrm{D}$ NMR $(1 \mathrm{H}$,
13C, COSY, HSQC and HMBC) and high resolution MS/ MS experiments (Additional file 3). Briefly, H8 and H10 appear as doublets at 7.15 and 6.65 ppm respectively, all the rest of the proton signals appear as singlets. The connectivity of the structures was mainly established using HMBC correlations. Key correlations observed include: $\mathrm{H} 2$ to $\mathrm{C} 4, \mathrm{C} 5$ and $\mathrm{C} 16$; $\mathrm{H} 4$ to $\mathrm{C} 2, \mathrm{C} 3, \mathrm{C} 5, \mathrm{C} 6, \mathrm{C} 14$ and $\mathrm{C} 16$, and weak correlation to $\mathrm{C} 15$; $\mathrm{H} 18$ to $\mathrm{C} 16, \mathrm{C} 17, \mathrm{C} 19$ and $\mathrm{C} 20$.

\section{Supplementary information}

Supplementary information accompanies this paper at https://doi. org/10.1186/s12934-020-01368-3.

Additional file 1: Overexpression/deletion of $m t m L$. Generation of plasmid $\mathrm{p} \Delta \mathrm{L}$. Generation of plasmid pDZL10. Figure S1. Comparison of MtmL with putative Acyl-CoA Ligases. Figure S2. Production of MTM by strains overexpressing $\mathrm{mtmL}$. Figure S3. Generation and analysis of mutant $S$. argillaceus $\Delta \mathrm{L}$.

Additional file 2: Chemical characterization of SEK15. Table S1. NMR assignment.

Additional file 3: Chemical characterization of 2-hydroxy nogalonic acid. Table S2. NMR assignment. Figure S4. Structure and key HMBC correlations. Figure S5. High resolution MS.

Additional file 4: Generation of gene cassette plasmids for 4DMPC. Table S3. Primers used in this work.

\section{Acknowledgements}

Not applicable.

\section{Authors' contributions}

CM and JAS conceived and designed the project; DZ conducted experiments; LS, YD and GLC performed isolation and structural characterization of compounds; DZ drafted the manuscript and CM and GLC edited it. All authors read and approved the final manuscript.

\section{Funding}

This work was supported by grants to C.M. from the Spanish Ministry of Economy and Competitiveness (Grants BIO2008-00269 and BIO2011-25398) and by the grant "Apoyo a grupos de excelencia", Principado de Asturias-FEDER (FC-15-GRUPIN14-014). D.Z. was recipient of a predoctoral fellowship from the Spanish Ministry of Economy and Competiveness.

Ethics approval and consent to participate

Not applicable.

Consent for publication

Not applicable.

\section{Competing interests}

The authors declare that they have no competing interests.

\section{Author details}

${ }^{1}$ Departamento de Biología Funcional e Instituto Universitario de Oncología del Principado de Asturias (I.U.O.P.A), University of Oviedo, Oviedo, Spain.

${ }^{2}$ Instituto de Investigación Sanitaria de Asturias (ISPA), Oviedo, Spain. ${ }^{3}$ Department of Chemistry, University of Warwick, Coventry CV4 7AL, UK. ${ }^{4}$ Warwick Integrative Synthetic Biology Centre, University of Warwick, Coventry CV4 7AL, UK. ${ }^{5}$ Department of Biochemistry and Molecular Biology, Monash University, Clayton, VIC 3800, Australia. 
Received: 31 January 2020 Accepted: 15 May 2020

Published online: 24 May 2020

\section{References}

1. Newman J, Cragg GM. Natural products as sources of new drugs over the last 25 years. J Nat Prod. 2007;70:461-77.

2. Fernández-Guizán A, Mansilla S, Barceló F, Vizcaino C, Núñez LE, Moris F, Gonzalez S, Portugal J. The activity of a novel mithramycin analog is related to its binding to DNA, cellular accumulation, and inhibition of Sp1-driven gene transcription. Chem Biol Interact. 2014;219:123-32.

3. Fajardo OA, Thompson K, Parapuram SK, Liu S, Leask A. Mithramycin reduces expression of fibro-proliferative mRNAs in human gingival fibroblasts. Cell Prolif. 2011;44:166-73.

4. Grohar PJ, Woldemichael GM, Griffin LB, Mendoza A, Chen Q-R, Yeung C, Currier DG, Davis S, Khanna C, Khan J, McMahon JB, Helman LJ. Identification of an inhibitor of the EWS-FLI1 oncogenic transcription factor by high-throughput screening. J Natl Cancer Inst. 2011;103:962-78.

5. Jia Z, Zhang J, Wei D, Wang L, Yuan P, Le X, Li Q, Yao J, Xie K. Molecular basis of the synergistic antiangiogenic activity of bevacizumab and mithramycin A. Cancer Res. 2007;67:4878-85.

6. Jia Z, Gao Y, Wang L, Li Q, Zhang J, Le X, Wei D, Yao JC, Chang DZ, Huang $\mathrm{S}$, Xie K. Treatment with combination of mithramycin A and tolfenamic acid promotes degradation of Sp1 protein and synergistic antitumor activity in pancreatic cancer. Cancer Res. 2010;70:1111-9.

7. Seznec J, Silkenstedt B, Naumann U. Therapeutic effects of the Sp1 inhibitor mithramycin A in glioblastoma. J Neurooncol. 2011;101:365-77.

8. Liu XJ, Li L, Liu XJ, Li Y, Zhao CY, Wang RQ, Zhen YS. Mithramycin-loaded mPEG-PLGA nanoparticles exert potent antitumor efficacy against pancreatic carcinoma. Int J Nanomedicine. 2017;12:5255-69.

9. Grohar PJ, Glod J, Peer CJ, Sissung TM, Arnaldez FI, Long L, Figg WD, Whitcomb P, Helman $\sqcup$, Widemann BC. A phase I/II trial and pharmacokinetic study of mithramycin in children and adults with refractory Ewing sarcoma and EWS-FLI1 fusion transcript. Cancer Chemother Pharmacol. 2017;80:645-52

10. Wohlert SE, Künzel E, Machinek R, Méndez C, Salas JA, Rohr J. The structure of mithramycin reinvestigated. J Nat Prod. 1999;62:119-21.

11. Lombó F, Menéndez N, Salas JA, Méndez C. The aureolic acid family of antitumor compounds: structure, mode of action, biosynthesis, and novel derivatives. Appl Microbiol Biotechnol. 2006;73:1-14.

12. Méndez C, González-Sabín J, Morís F, Salas JA. Expanding the chemical diversity of the antitumor mithramycin by combinatorial biosynthesis and biocatalysis: the quest for mithralogs with improved therapeutic window. Planta Med. 2015;81:1326-38.

13. Baig I, Perez M, Braña AF, Gomathinayagam R, Damodaran C, Salas JA, Méndez C, Rohr J. Mithramycin analogues generated by combinatorial biosynthesis show improved bioactivity. J Nat Prod. 2008;71:199-207.

14. Núñez LE, Nybo SE, Gonzalez-Sabin J, Pérez M, Menéndez N, Braña AF, He M, Morís F, Salas JA, Rohr J, Méndez C. A novel mithramycin analogue with high antitumor activity and less toxicity generated by combinatorial biosynthesis. J Med Chem. 2012;55:5813-25.

15. Pérez M, Baig I, Braña AF, Salas JA, Rohr J, Méndez C. Generation of new derivatives of the antitumor antibiotic mithramycin by altering the glycosylation pattern through combinatorial biosynthesis. ChemBioChem. 2008;9:2295-304.

16. Remsing LL, González AM, Nur-e-Alam M, Fernández-Lozano MJ, Braña AF, Rix U, Oliveira MA, Méndez C, Salas JA, Rohr J. Mithramycin SK, a novel antitumor drug with improved therapeutic index, mithramycin SA, and demycarosyl-mithramycin SK: three new products generated in the mithramycin producer Streptomyces argillaceus through combinatorial biosynthesis. J Am Chem Soc. 2003;125:5745-53.

17. Osgood CL, Maloney N, Kidd CG, Kitchen-Goosen S, Segars L, Gebregiorgis M, Woldemichael GM, He M, Sankar S, Lessnick SL, Kang M, Smith M, Turner L, Madaj ZB, Winn ME, Núñez LE, González-Sabín J, Helman $L$, Morís F, Grohar PJ. Identification of mithramycin analogues with improved targeting of the EWS-FLI1 transcription factor. Clin Cancer Res. 2016;22:4105-18

18. Pandiella A, Morís F, Ocaña A, Núñez LE, Montero JC. Antitumoral activity of the mithralog EC-8042 in triple negative breast cancer linked to cell cycle arrest in G2. Oncotarget. 2015;6:32856-67.
19. Fernández-Guizán A, Lopez-Soto A, Acebes-Huerta A, Huergo-Zapico L, Villa-Alvarez M, Núñez LE, Moris F, González S. Pleiotropic anti-angiogenic and anti-oncogenic activities of the novel mithralog demycarosyl-3D-ssD-digitoxosyl-mithramycin SK (EC-8042). PLoS ONE. 2015;10:e0140786.

20. Tornin J, Martínez-Cruzado L, Santos L, Rodríguez A, Núñez LE, Oro P, Hermosilla MA, Allonca E, Fernández-García MT, Astudillo A, Suarez C, Morís F, Rodríguez R. Inhibition of SP1 by the mithramycin analog EC-8042 efficiently targets tumor initiating cells in sarcoma. Oncotarget. 2016:7:30935-50.

21. Flórez AB, Álvarez S, Zabala D, Braña AF, Salas JA, Méndez C. Transcriptional regulation of mithramycin biosynthesis in Streptomyces argillaceus: dual role as activator and repressor of the PadR-like regulator MtrY. Microbiology. 2015;161:272-84.

22. Lombó F, Braña AF, Méndez C, Salas JA. The mithramycin gene cluster of Streptomyces argillaceus contains a positive regulatory gene and two repeated DNA sequences that are located at both ends of the cluster. J Bacteriol. 1999;181:642-7

23. Zabala D, Braña AF, Flórez AB, Salas JA, Méndez C. Engineering precursor metabolite pools for increasing production of antitumor mithramycins in Streptomyces argillaceus. Metab Eng. 2013;20:187-97.

24. Novakova R, Núñez LE, Homerova D, Knirschova R, Feckova L, Rezuchova B, Sevcikova B, Menéndez N, Morís F, Cortés J, Kormanec J. Increased heterologous production of the antitumoral polyketide mithramycin A by engineered Streptomyces lividans TK24 strains. Appl Microbiol Biotechnol. 2018;102:857-69.

25. Palazzotto E, Tong Y, Lee SY, Weber T. Synthetic biology and metabolic engineering of actinomycetes for natural product discovery. Biotechnol Adv. 2019;37(6):107366.

26. Blanco G, Fu H, Mendez C, Khosla C, Salas JA. Deciphering the biosynthetic origin of the aglycone of the aureolic acid group of anti-tumor agents. Chem Biol. 1996;3:193-6.

27. Lombó F, Blanco G, Fernández E, Méndez C, Salas JA. Characterization of Streptomyces argillaceus genes encoding a polyketide synthase involved in the biosynthesis of the antitumor mithramycin. Gene. 1996;172:87-91.

28. Wang G, Chen J, Zhu H, Rohr J. One-pot enzymatic total synthesis of presteffimycinone, an early intermediate of the anthracycline antibiotic steffimycin biosynthesis. Org Lett. 2017;19:540-3.

29. Abdelfattah MS, Rohr J. Premithramycinone $G$, an early shunt product of the mithramycin biosynthetic pathway accumulated upon inactivation of oxygenase MtmOll. Angew Chem Int Ed Engl. 2006;45:5685-9.

30. Lombó F, Künzel E, Prado L, Braña AF, Bindseil KU, Frevert J, Bearden D, Méndez C, Salas JA, Rohr J. The novel hybrid antitumor compound premithramycinone $\mathrm{H}$ provides indirect evidence for a tricyclic intermediate of the biosynthesis of the aureolic acid antibiotic mithramycin. Angew Chem Int Ed Engl. 2000;39:796-9.

31. Prado L, Lombó F, Braña AF, Méndez C, Rohr J, Salas JA. Analysis of two chromosomal regions adjacent to genes for a type II polyketide synthase involved in the biosynthesis of the antitumor polyketide mithramycin in Streptomyces argillaceus. Mol Gen Genet. 1999;261:216-25.

32. González A, Remsing LL, Lombó F, Fernández MJ, Prado L, Braña AF, Künzel E, Rohr J, Méndez C, Salas JA. The mtmVUC genes of the mithramycin gene cluster in Streptomyces argillaceus are involved in the biosynthesis of the sugar moieties. Mol Gen Genet. 2001;264:827-35.

33. Lombó F, Siems K, Braña AF, Méndez C, Bindseil K, Salas JA. Cloning and insertional inactivation of Streptomyces argillaceus genes involved in the earliest steps of biosynthesis of the sugar moieties of the antitumor polyketide mithramycin. J Bacteriol. 1997;179:3354-7.

34. Blanco G, Fernández E, Fernández MJ, Braña AF, Weissbach U, Künzel E, Rohr J, Méndez C, Salas JA. Characterization of two glycosyltransferases involved in early glycosylation steps during biosynthesis of the antitumor polyketide mithramycin by Streptomyces argillaceus. Mol Gen Genet. 2000;262:991-1000.

35. Remsing LL, Garcia-Bernardo J, Gonzalez A, Künzel E, Rix U, Braña AF, Bearden DW, Méndez C, Salas JA, Rohr J. Ketopremithramycins and ketomithramycins, four new aureolic acid-type compounds obtained upon inactivation of two genes involved in the biosynthesis of the deoxysugar moieties of the antitumor drug mithramycin by Streptomyces argillaceus, reveal novel insights into post-PKS tailoring steps of the mithramycin biosynthetic pathway. J Am Chem Soc. 2002;124:1606-14.

36. Lozano MJ, Remsing LL, Quirós LM, Braña AF, Fernández E, Sánchez C, Méndez C, Rohr J, Salas JA. Characterization of two polyketide 
methyltransferases involved in the biosynthesis of the antitumor drug mithramycin by Streptomyces argillaceus. J Biol Chem. 2000;275:3065-74.

37. Rohr J, Weißbach U, Beninga C, Künzel E, Siems K, Bindseil KU, Lombó F, Prado L, Braña AF, Méndez C, Salas JA. The structures of premithramycinone and demethylpremithramycinone, plausible early intermediates of the aureolic acid group antibiotic mithramycin. Chem Commun. 1998:3:437-8

38. Daum M, Peintner I, Linnenbrink A, Frerich A, Weber M, Paululat T, Bechthold A. Organisation of the biosynthetic gene cluster and tailoring enzymes in the biosynthesis of the tetracyclic quinone glycoside antibiotic polyketomycin. ChemBioChem. 2009;10:1073-83.

39. Menéndez N, Nur-e-Alam M, Braña AF, Rohr J, Salas JA, Méndez C. Biosynthesis of the antitumor chromomycin A3 in Streptomyces griseus: analysis of the gene cluster and rational design of novel chromomycin analogs. Chem Biol. 2004;11:21-32

40. Pickens LB, Kim W, Wang P, Zhou H, Watanabe K, Gomi S, Tang Y. Biochemical analysis of the biosynthetic pathway of an anticancer tetracycline SF2575. J Am Chem Soc. 2009;131:17677-89.

41. Pickens LB, Tang Y. Oxytetracycline biosynthesis. J Biol Chem. 2010:285:27509-15

42. Xu W, Raetz LB, Wang P, Tang Y. An ATP-dependent ligase catalyzes the fourth ring cyclization in tetracycline biosynthesis. Tetrahedron. 2016;72:3599-604.

43. McDaniel R, Ebert-Khosla S, Hopwood DA, Khosla C. Engineered biosynthesis of novel polyketides. Science. 1993;262:1546-50.

44. Gullón S, Olano C, Abdelfattah MS, Braña AF, Rohr J, Méndez C, Salas JA. Isolation, characterization, and heterologous expression of the biosynthesis gene cluster for the antitumor anthracycline steffimycin. Appl Environ Microbiol. 2006;72:4172-83.

45. Olano C, Lombó F, Méndez C, Salas JA. Improving production of bioactive secondary metabolites in actinomycetes by metabolic engineering. Metab Eng. 2008;10:281-92.

46. Zhou H, Li Y, Tang Y. Cyclization of aromatic polyketides from bacteria and fungi. Nat Prod Rep. 2010;27:839-68.

47. Caldara-Festin G, Jackson DR, Barajas JF, Valentic TR, Patel AB, Aguilar S, Nguyen M, Vo M, Khanna A, Sasaki E, Liu HW, Tsai SC. Structural and functional analysis of two di-domain aromatase/cyclases from type II polyketide synthases. Proc Natl Acad Sci USA. 2015;112:E6844-51.

48. Rohr J, Mendez C, Salas JA. The biosynthesis of aureolic acid group antibiotics. Bioorg Chem. 1999;27:41-54

49. Zhang $W$, Li Y, Tang Y. Engineered biosynthesis of bacterial aromatic polyketides in Escherichia coli. Proc Natl Acad Sci USA. 2008;105:20683-8.

50. Lomovskaya N, Doi-Katayama Y, Filippini S, Nastro C, Fonstein L, Gallo M, Colombo AL, Hutchinson CR. The Streptomyces peucetius dps $Y$ and
dnrX genes govern early and late steps of daunorubicin and doxorubicin biosynthesis. J Bacteriol. 1998;180:2379-86.

51. Ma HM, Zhou Q, Tang YM, Zhang Z, Chen YS, He HY, Pan HX, Tang MC, Gao JF, Zhao SY, Igarashi Y, Tang GL. Unconventional origin and hybrid system for construction of pyrrolopyrrole moiety in kosinostatin biosynthesis. Chem Biol. 2013;20:796-805.

52. Zhang W, Watanabe K, Wang CC, Tan Y. Investigation of early tailoring reactions in the oxytetracycline biosynthetic pathway. J Biol Chem. 2007:282:25717-25.

53. Künzel E, Wohlert SE, Beninga $C$, Haag S, Decker $H$, Hutchinson $C R$, Blanco G, Mendez C, Salas JA, Rohr J. Tetracenomycin M, a novel genetically engineered tetracenomycin resulting from a combination of mithramycin and tetracenomycin biosynthetic genes. Chem Eur J. 1997;3:1675-8.

54. Sultana A, Kallio P, Jansson A, Wang JS, Niemi J, Mäntsälä P, Schneider G. Structure of the polyketide cyclase SnoaL reveals a novel mechanism for enzymatic aldol condensation. EMBO J. 2004;5(23):1911-21.

55. Kieser T, Bibb MJ, Buttner MJ, Chater KF, Hopwoo DA. Practical Streptomyces genetics. Norwich: The John Innes Foundation; 2000.

56. Fernández E, Weibbach U, Sánchez Reillo C, Braña AF, Méndez C, Rohr J, Salas JA. Identification of two genes from Streptomyces argillaceus encoding two glycosyltransferases involved in the transfer of a disaccharide during the biosynthesis of the antitumor drug mithramycin. J Bacteriol. 1998;180:4929-37.

57. García B, González-Sabín J, Menéndez N, Braña AF, Núñez LE, Morís F, Salas JA, Méndez C. The chromomycin CmmA acetyltransferase: a membrane-bound enzyme as a tool for increasing structural diversity of the antitumour mithramycin. Microb Biotechnol. 2011;4:226-38.

58. Sambrook J, Russell DW. Molecular cloning: a laboratory manual. 3rd ed. Cold Spring Harbor, NY: Cold Spring Harbor Laboratory; 2001.

59. Vieira J, Messing J. New pUC-derived cloning vectors with different selectable markers and DNA replication origins. Gene. 1991;100:189-94.

60. Menéndez N, Nur-e-Alam M, Fischer C, Braña AF, Salas JA, Rohr J, Méndez C. Deoxysugar transfer during chromomycin A3 biosynthesis in Streptomyces griseus subsp. griseus: new derivatives with antitumor activity. Appl Environ Microbiol. 2006;72:167-77.

61. Quirós LM, Aguirrezabalaga I, Olano C, Méndez C, Salas JA. Two glycosiltransferases and a glycosidase are involved in oleandomycin modification during its biosynthesis by Streptomyces antibioticus. Mol Microbiol. 1998;28:1177-85.

\section{Publisher's Note}

Springer Nature remains neutral with regard to jurisdictional claims in published maps and institutional affiliations.
Ready to submit your research? Choose BMC and benefit from:

- fast, convenient online submission

- thorough peer review by experienced researchers in your field

- rapid publication on acceptance

- support for research data, including large and complex data types

- gold Open Access which fosters wider collaboration and increased citations

- maximum visibility for your research: over $100 \mathrm{M}$ website views per year

At BMC, research is always in progress.

Learn more biomedcentral.com/submissions 